\title{
Maintaining an Effective Online Learning Environment and the Role of the E-Tutor: The University of Education, Winneba Experience
}

\author{
Salome O. Essuman (corresponding author) \\ University of Education, Winneba \\ P. O. Box 25, Winneba. Ghana
}

Email: sessuman@uew.edu.gh, sallyessuman@gmail.com

Patricia Appiah-Boateng

University of Education, Winneba

P. O. Box 25, Winneba. Ghana

Email: patricia.ananga1@gmail.com

Received: August 27, 2014 Accepted: September 9, 2014 Published: November xx, 2014

doi:10.5296/jet.v2i1.6685 URL: http://dx.doi.org/10.5296/jet.v2i1.6685

\begin{abstract}
Understanding the importance of the changing role of tutors about the skills needed to achieve an effective online teaching and learning is paramount to a successful online course and programme at large. This paper explores the new roles and responsibilities of some faculty members of the University of Education, Winneba (UEW), who have been engaging in online tutoring activities for two years. There is an increasing quest to bring everyone on board for the growing interest in e-learning at UEW. However much is not known about the experiences of e-tutors regarding the roles they have been playing in online facilitation. The successful stories, the challenges and what mechanisms exist for improving the practice are very key. In the paper, we discuss the success factors and challenges and approaches required to support lecturers. A qualitative approach using a semi-structured interview guide was employed in collecting data from ten (10) purposively sampled lecturers who teach different courses at UEW. Among the key findings are that it is the tutors' role to initiate the learning processes, moderate students' participation and lead students in discovery mode of learning. Further, as managers and leaders in the learning process they bring students together through
\end{abstract}


group work and other forms of social interaction. However, it emerged that special support and communication systems should be established for both tutors and students to enable them interact effectively. There is the need to provide tutors with continuous professional training and counseling as most of them are new to this mode of education delivery. Again, it emerged that there is ample opportunity to give diverse materials to students to read before any interaction either face-to-face or online. It was proposed that potential tutors should be IT savvy, sharpen their skills and think within an IT context. It is recommended that there should be motivation and recognition for lecturers who tutor online since this mode of teaching is time consuming and very demanding.

Keywords: e-learning, online tutoring, e-tutor, tutoring skills

\section{Background}

The growth of e-learning is directly linked to the increasing access to new communication technologies which have the capacity to support multimedia resource-based teaching and learning. Many individuals, including teachers are increasingly using these devices in their teaching and learning experiences.

Presently, there is hardly any higher educational institution (public or private) in Ghana, that is not thinking of introducing one form or the other of an internet-based teaching and learning approach; either e-learning or m-learning or online learning into its educational programme delivery. This is because the contemporary student population, who are popularly, referred to as the 'Google generation' or 'Millennials' expect to see some of these technologies used in their educational settings. The University of Education, Winneba (UEW) is no exception and has adopted this approach, specifically the blended mode of teaching and learning using one form or the other of modern communication technology. In this regard, some lecturers in the conventional face-to-face programmes have begun adopting the blended mode to enrich their teaching and to increase the flexibility of their lectures. Similarly, some others in the distance education department have also adopted that mode for its new programmes.

In 2012, the Centre for Distance Education at the University started the blended mode of delivering its Master of Education (M.Ed.) programmes in English, Mathematics and Science Education by distance. The mode consisted of once-a-month face-to-face tutorials and some hours per week of an online delivery component. This is because the University had installed the MOODLE learning management system on its internet server for the community. The benefits of using course management systems such as MOODLE as learning tools in the world today cannot be over emphasized especially in developing countries where the cost of proprietary LMSs are beyond the reach of the Institutions within those countries. It is useful for students to view MOODLE as a virtual classroom where learning materials and activities can be made available by a lecturer for the student to interact with. The benefit of this virtual classroom or platform for students is that they can have access to it from anywhere in the world at any time provided they have access to an Internet connection and a web browser. In fact, many faculty members, though briefly trained before the start of the programme, were being tasked to tutor online. If anything at all, to use this blended mode of teaching and learning in their practice. But as argued by Bennett and Marsh (2002), were tutors being 
asked to 'run before they walk' or what? This is because the majority of them were new to online teaching and do not have the background experience of online learning upon which they could draw on in their current practice. Presently, the attitude of some tutors working with the Centre shows that support and motivation are very necessary components for a successful implementation of the programme. The study therefore seeks to explore their experiences as e-tutors and the role they have been playing in online facilitation and the implications for maintaining an effective online environment as well as for policy guidelines.

\subsection{Literature review}

Studies in the literature have indicated that there are three areas of faculty support, which are basically needed when it comes to online teaching and learning. They include: 1) courseware development and teaching support, 2) management of online materials and resources, and 3) technical support (Zawacki-Richter, 2004). Zawacki-Richter further states that the development and promotion of online teaching and learning can only be realized by a support strategy that takes effect from both the top-down and from the bottom-up with the introduction of incentive systems for participation in online teaching. In other words, there should be the institutional framework created through a consistent top-down approach to meet the needs of faculty involved in the exercise, as well as a change culture among faculty members through teamwork and colleagues learning from one another.

For the M.Ed. programme under discussion, the blended mode of teaching and learning has been adopted with the tutor: student ratio of 1:10 though this differs from course to course. Tutors teaching core courses had more students to teach as compared to the elective courses in the various subject areas. But it is to be noted that the literature suggests the ideal number for online tutoring to be less than 25-30 (Anderson, 2004 in O'Hare, 2011) and this is not without challenges and limitations. This is presumed to be for solely online. E-learning and its impact on tutors is an area to be critically explored particularly in our context. This is because what makes its implementation so challenging is that tutors are being tasked to acquire new competencies, skills, attitudes and roles in diverse ways to suit new specific situations during the teaching sessions. JoAnn Harrison in Pushpanathan (2012) suggests that the e-teacher (tutor) will not be 'the person who knows all the answers and decides what the question will be' but it is the e-teacher who 'becomes an expert learner' in a facilitative and collaborative e-learning environment.

\subsection{Tutors' Role and Responsibilities in Online Tutoring}

Online tutoring and leadership have been widely discussed in many areas of internet-based learning where alternative names have been used in connection with the role that the tutor plays in online interactions. These names include: online facilitator, e-moderator, online instructor, e-tutor, e-teacher, e-coach, e-mentor and others (Salmon, 2000; McPherson \& Nunes, 2004; Pushpanathan, 2012; Denis et al., 2004). Again, in the literature many writers including O'Hare (2011); Denis et al. (2004); Goold et al. (2010) have argued that the traditional knowledge required by the university tutor was insufficient to tutor online since interacting in an online environment is very different from interacting in a face-to-face classroom. O'Neil in Goold et al. (2010) suggests that online instructor's role requires a 
paradigm shift in perceptions of instructional time and space, virtual management techniques and ways of engaging students through virtual communications. What the above writers seem to suggest is that tutors online have to assume certain roles and ways of interacting with students that require a new range of skills and attributes that arise from the 'cyber dynamics of the online world'. The question is: do the tutors on the programme under study have these characteristics?

The online tutor is described as a person who is responsible for responding to and building on the contributions of online discussions. He or she facilitates the learner's transition into the online learning environment as well as through the complexities of the learning activities. The roles assigned to e-tutors include: 'pastoral care' of students in terms of advising them about course choices, marking students' assignments and coursework, providing feedback on submitted materials, moderating conferences, acting as mentors to less experienced colleagues and doing quality control of other e-tutors' work (Denis et al., 2004). Other wide range of roles associated with the online tutor includes: promoter, manager, negotiator, facilitator, discussion leader, and many more. It can be gathered again from the above that the role of the e-tutor is a complex one and challenges associated with it should not be underestimated. As such, tutors who are new to online teaching without the relevant background or experience or minimal in online pedagogy are really 'being asked to run before they walk' as alleged by Bates (2000) and Bennett and Marsh (2002).

Berge in O'Hare (2011) suggests four main categories as roles of the e-tutor. They are:

- Social - where students are encouraged in a friendly social environment with teachers affirming and recognizing input and providing opportunities for group cohesiveness to develop

- Managerial - provision of objectives, setting of timelines and defining of rules and roles

- Technical - ensuring that all participants develop confidence in the network systems and software

- Pedagogical - where teachers provide insights from the subject knowledge and experience using questions and probes to encourage students responses

Similarly, Hootstein in O'Hare (2011) proposes the model where tutors could be linked with four different 'pairs of shoes' as “"

- Instructor - providing informative feedback

- Social Director - fostering collaborative learning

- Programme Manager - developing and providing study guides

- Technical assistant - helping the learners to become proficient with the technology.

From these reviews, Denis et al. (2004) propose that the roles could be categorized as 'Central Roles' (which relate to interaction) and 'Peripheral Roles' (previous to or after interactions). Again, what these reviews seem to highlight is the contextualized nature of the 
tutor from the perspective of the tutor-students interactions in the teaching and learning situations. There are many more other models of online tutors and their roles that individuals have propounded. However, Salmons (2003) has a model of teaching online, which many people seem to be citing. She describes the process as developing over five stages: 1) access and motivation, 2) socialization, 3) information exchange, 4) knowledge construction and 5) development, where each stage demands different tutoring skills, including setting up and accessing skills, searching, sending and receiving message skills, conferencing skills and many more. It is clear that some of these roles overlap from one researcher to another suggesting a blurring of the boundaries of these roles.

Contrarily, Moule (2007) challenges the five-stage model for e-learning with the 'e-ladder' model developed as part of her doctoral research within higher education setting in UK. The 'e-learning ladder' was based on the theoretical underpinning of Communities of Practice by Wenger (1998). The ladder starts with an 'instructivist' approach to learning, which is an isolated approach to the top of the ladder where a constructivist or interactive learning approach is attained. In her view, skills needed include: ICT access, IT skills, technical support, facilitation, longevity of engagement and group working skills. All these skills would be increasing as one climbs 'the e-ladder'. Nonetheless, she acknowledges that not all e-learning is constructivist or course-based and reflects the range of e-based learning materials. Compared to the skills needed on the five-stage model, there seems to be an overlapping of the skills.

On the other hand, Cheung and Hew (2008) also argue that the individual characteristics of the e-tutor such as 'habits of mind', personal attributes including awareness of own thinking; accuracy seeking; open mindedness; taking a position and being sensitive to others, all influence how online tutors interact with learners in online discussions. In a study conducted, they found that 'aware of thinking' and 'open minded' were the most prevalent habits of mind of tutors involved (Cheung \& Hew, 2010). As can be learned from the discussions, to be effective and successful as an online tutor one needs to provide an engaging learning environment that retains students and assists them to complete their courses successfully. The creation of an effective virtual learning environment calls for an understanding of learners' needs, their backgrounds, knowledge of skills they bring on board and for negotiating online and many more. The tutor then has to build that sense of community for all learners providing them with a sense of belonging, identity, emotional connection and well being (O'Hare, 2011).

On the other hand, Nunes et al. (2000) in McPherson and Nunes (2004) have argued that it is not enough that tutors are prepared for online learning alone, the learners also need preparation. They continue their proposition that students are expected to develop high cognitive skills such as negotiation of meaning, long-life learning, reflective analysis and meta-cognition, basic use of computer mediated technology, online social skills, online etiquette, web navigation and web searching. These skills are branded as Networked Information and Communication Literacy Skills (NICLS) and they are supposed to be acquired in addition to the traditional educational skills of reading, writing, spelling, numeracy, handwriting, as an essential aspect of daily networked activity in the online 
learning environment. They stress that failure to address this issue in online learning leads to much frustration for learners and eventually to lower levels of success for the online learning courses (Hara \& Kling, 1999 in McPherson \& Nunes, 2004).

In addition to the well-prepared tutors and learners, it is believed that successful e-learning also requires pedagogical sound, well-designed online resources. These resources include information resources that learner might need at a particular moment in learning, thinking or designing new ideas, while engaging in a particular learning activity. Kommers, 1996, in McPherson \& Nunes, 2004, proposes that modern approaches to teaching and learning such as constructivism, problem-based learning and experiential learning all assume that knowledge is acquired through social negotiation, experience and reflection, and the appropriate resources will have to be provided for that to take place.

\subsection{Context of and Aim of Study}

The study context was at the University of Education, Winneba, where some faculty members had adopted the blended mode of delivering distance education courses and some regular courses. With the distance education courses, it was mandatory that at least eight (8) hours per week be used in online tutoring. An informal interaction with some students revealed that most tutors were not following the directives of the University. The aim of this study therefore was to explore the views and experiences of faculty members in e-tutoring to understand issues regarding their roles and leadership in online tutoring and how that should inform policy and practice. Also it is to help us document their experiences, and offer the needed support system that has to be put in place for future cohorts.

\subsection{Research Questions}

The research questions employed to elicit data from respondents include:

- What factors influence online tutors on blended mode of teaching?

- What are the main roles and responsibilities of online tutors?

- How do online tutors interact and monitor their students' learning?

- What are the implications of online teaching at UEW?

\subsection{Constructivist Approach to e-Learning}

This study was based on the Constructivist learning theory. Research has shown that constructivism learning theory which is focused on knowledge construction based on learner's previous experience, can be drawn on in e-learning to understand how learning among learners occur (Harman \& Koohang, 2005; Hung, 2001; Hung \& Nichani, 2001). According to Woolfolk (1993), one of the critical concepts is that students can actively construct their own knowledge where the students' mind uses information from the outside world to determine what the student will learn. Thus, ensuring that learning is moved from being passive reception teaching to an active mental work. Carswell $(2001$, p.2) argues that reality is in the learner's mind and the goal of learning is to construct in the learner's mind its own, unique conception of events. This suggests that learners need to become independent in order to be able to construct their own learning. This agrees with Koyanagi (n.d.) who 
believes in the independent exploration of the content by students that will lead to a deeper understanding. To enable students survive this independence, there is the need to create a meaningful environment that includes communication and collaboration (Gold, 2001). The instructor is therefore supposed to create a good environment by posing problems and providing relevant information to enable the student understand the relevance of the new information (Mayer, 1996). This theory fits into this study, which looks at maintaining an effective online learning and the role of the e-tutor.

\section{Methodology}

A qualitative interpretive approach as described by Marshall and Rossman (2006) was adopted because the focus was on the perceptions, views and experiences of individuals who were teaching online in different courses. As indicated earlier on in the text, these lecturers are new to online pedagogy and though there were series of training sessions organized for them some of them seemed to have abandoned the knowledge and skill. In all, ten (10) lecturers who teach different courses from five (5) departments namely: Mathematics, ICT, Home Economics, Social Studies and Early Childhood Education were purposively sampled to be interviewed for the study. These participants are among the fifty five (55) lecturers who were trained to use the MOODLE platform but only about twenty (20) of them have actually been using it in teaching their courses. A semi-structured interview guide was used at different interview times on a one-on-one basis to elicit information from them. The interviews were audio-recorded and later transcribed verbatim. It needs to be mentioned that these lecturers gave their consent before the exercise was carried out and they were assured of confidentiality and anonymity. The transcripts were analyzed using a content analysis approach by both inductive and deductive approaches. Categories and themes that emerged from the interview responses were used in the analysis.

To guard against bias and to avoid any influence on the data, interviewees were urged to be honest and objective as much as possible. The interviewer also comported herself to stay disinterested in responses given by interviewees. Interviewees were assured of anonymity, as pseudonyms were to be used for them with regard to their responses. These measures contributed to the validity of the data collected. Further, the careful sampling of interviewees, using of audio-recorder to record interviews, storage and retrieval of data and the use of appropriate instruments for the interviews ensured internal and content validity.

\subsection{Data Analysis, Findings and Discussions}

From the interview discussions, lecturers were asked to share their experiences, views, challenges, roles and responsibilities that they have been involved in as online tutors. Further, they were asked to comment on the kind of skills needed by the online tutor in teaching; how they interacted with students online/offline and outline the positive and challenging aspects of online teaching and learning. Some of the emerging themes that lecturers came up with include: skills needed by a tutor to be an effective online tutor, characteristics of an online tutor, tutors' modes of interaction - such as initiating interactions, supporting collaborative learning of students, ensuring self-directed/regulated learning and various constraints of teaching online. It needs to be mentioned that some categories were overlapping, as such only 
major themes are discussed in the sections below.

\subsection{The Roles of the Online Tutor - (Skills and Qualities of Online Tutors)}

When asked to outline some of the roles and responsibilities that an online tutor could be involved in from their [interviewees'] perspective, almost all of them listed quite a number of roles as found in the literature discussed above. This is what some of them had to say:

I think an online tutor has to be a good designer, he should be able to design authentic activities for the students to follow, and he should be a facilitator, he should be able to facilitate the whole process; instead of teaching he has to lead the students into arriving at what he wants to bring across. He has to also be a good communicator in writing and speaking because the students will rely on what he says because you have limited time to discuss with the students because you are always encouraging them to go on ... [Reter, Maths.]

... I'm responsible for initiating the learning process. I'm responsible for providing instant feedback to the students because that will encourage them to learn. I'm also responsible for keeping the records of my students because at the final analysis you have to provide information about their assessment process. So there are a lot of responsibilities you need to go through ... [Yug, H.Econs]

The above quotations and what others also mentioned confirm Berge in O'Hare's (2011) suggestion that the roles of the e-tutor expand to include: 1) social-where students are encouraged in a friendly social environment with teachers affirming and recognizing input and providing opportunities for group cohesiveness [This is as indicated in the quotation by Reter, (Maths)]. The tutor has to develop managerial responsibilities-where there is the provision of objectives, setting of timelines and defining of rules and roles of learners. In other words, the roles of the online tutor are diverse and multi tasking similar to the face-to-face tutor. It is implied in these roles that the tutor is a leader and guide in the learning process of the learners and in the learning environment. However, in answering this major question, interviewees seemed not to have emphasized the pedagogical presence or role of the tutor online. In other words, the strategies needed to achieve these roles, though some qualities were listed. Yet still, the strategies seem to be implied in some statements as in the case of Mijwi (see below) from the social studies department.

You must be a committed person, as one who designs the course online, you must be committed to following the activities and the processes as to how you did it. If you do that once, next time when you are with your students they will all follow the same process; like I said, you should also be able to relate with the students in a very friendly manner, your relationship with the students should be cordial. You should also know the subjects matter because some of the students go ahead of you and if they realize they appear to be better than 
you, they will not follow whatever you are teaching them. You should possess the ability to group student's based on their strengths and weaknesses so that it will facilitate the whole process. You should also be good at searching for information online so that you go for the latest and authentic information ... [Mijwi, S.Studies]

In the above quotation, the interviewee seems to highlight the pedagogical presence of online tutors in designing course outlines that take into consideration learners' learning styles and abilities. A tutor with this background knowledge would employ a variety of teaching strategies such as group work or project work, discussion forum, individual work, mind mapping and many more on the learning platform. It is believed that there are many different learning tools on the platform for the tutor to use and it requires the knowledge and skill of the tutor to employ these. Thus, EphAid, an ICT tutor iterates in his response the critical need for IT skills of the online tutor:

First of all, I think IT skills are important, and you need to be confident in the use of the internet, because most of the time we do go to look for information online... you know... you need to know about some websites where you can find relevant information, reputable websites ...[EphAid, ICT]

Berge in O'Hare (2011) argues that pedagogical skills needed by the online tutor centre on teachers providing insights from the subject matter and their experiences thereby using questions and probes to encourage students' responses. In this vein, teaching strategies that emphasize high order thinking, problem solving thinking and open-ended questioning and others as propounded in Bloom's taxonomy of teaching should be employed. Again, it is implied in this finding that metacognitive approach to teaching is necessary for online tutors. Again, from Reter (Maths.) and Addo's (ICT) viewpoint, social presence is critical for the online tutor in enhancing the learning environment. They iterate that:

Well, social skills... the interactions with the students... are important. There again, I see a few times I've had to use the chat feature when I'm not available and I've encouraged students to send me e- mails if they have any questions. But again, it's a different paradigm as regards the social skills that's required in the classroom...you know... face to face... [Reter, Maths]

... because I meet them face to face, so aside the face to face I meet them in a chat room where I'm going to be there for about one hour (they all know I'll be there) yes, they know I'll be there because usually it's stated on the portal. But aside that, they also send me emails so from time to time when I receive emails I respond and then whenever I log into the course, which I do almost every day, I'll check what the students have been doing... [Addo, ICT]

Based on the findings above, it is clear that the online tutor has the responsibility to build a 
sense of belonging in the virtual learning environment. The social presence, which is emphasized so much in the literature as a means of fostering and enhancing students' engagement is confirmed by these responses. This finding has implications for how such resources would be procured in UEW to assist e-tutors give out their best.

\subsection{Modes of Interaction}

Since tutors were already lecturers on the regular face-to-face teaching, the researchers wanted to find out the kind of interactions they were having with students in the online environment. Therefore, they were asked to share these kinds of interaction. It is to be noted that all interviewees responded that they engaged meaningfully and successfully with students and that their involvements with students centered on chats, forum and many other forms of discussions. Some comments were that:

One of the things I do is that I follow statistics that Moodle provides to know who has not done what and when, so I know whether they are going online frequently or not ... and I also put up forum discussions where I put a dead line to it, so that if you don't come up and contribute, then, you don't gain a score, maybe two (2) marks or five (5) marks or something like that so it forces them to come online. And then I also read what they put on and from time to time I try to redirect the discussion because at times you find that it goes in an off direction... yes ..., sometimes if you find the discussion going off balance, you try to redirect them back to what you want, you chip in a comment here and there, so we do that... [JOY, ECD]

... because I meet them face to face, so aside the face to face I meet them in a chat room where I'm going to be there one hour (they all know you'll be there?) yes, they know I'll be there because usually it's stated on the portal. But aside that, they also send me emails so from time to time when I receive emails I respond and then whenever I log into the course, which I do almost every day, I'll check what the students have been doing... [Addo, ICT]

These responses and others highlight the different kinds of interaction that the tutors engaged in with their students. It is evident that they encouraged student-to-student interaction as well as tutor-to-student interaction, just as practiced in the face-to-face learning environment. In this vein, collaborative learning was expected to be implemented in their learning process.

\subsection{Collaborative Learning and Peer Interactions}

Some of the tools employed by tutors to foster the learning engagements included: emails, chats and forum discussions.

It is my policy which, I had given them a particular time that I'm available on-line so that we could be chatting, otherwise students could go with their colleagues and it is my policy that, when you go online, the issues that you chat on should be related to issues on the course not 
anything outside..., so as much as possible I try to regulate them, so that it is purely academic things that we discuss ... [Nushen, H/Econs]

I start slowly by asking them to design a short lesson for about five minutes on a concept like fraction and so in their groups they are required to [usually I have nine groups] come out with their own project and then in class I try to explain the various limitations in the group work for all to learn that is how we help them make it better before we proceed to the next stage. So I think the moodle platform has been very helpful in encouraging collaborative learning... [Reter, Maths]

Yes. Because the courses we teach are quite practical, we almost in every course that I take, I give them group work to do online. Usually, I give them a project work which forces them to practise the skills that they learn in each lesson and then they present a report in class during the face-to-face ... [Latso, ECD]

The tutors in these quotations seem to share their experiences in how they have been using the blended mode of teaching to assist students in self-regulated learning instead of them always answering their questions as in the face-to-face mode. This appears to emphasize the importance of discovery learning and collaborative learning as well. In the quotations, the tutors seem to highlight how they encourage student participation in lesson delivery by allowing them to work in groups. Project works, which took longer periods were also encouraged by the tutors. Tutors again felt that they encouraged constructive feedback from participants online as they interacted with them. This is what one interviewee said:

In most of the forums I tell students that they're free to comment on an opinion somebody had expressed so if somebody express an opinion and they want to comment on it I give them that liberty to do so to be able to reply to what the person has said; even in the chats I do the same ...[Nushen, H/Econs].

In addition, tutors were of the view that this mode of teaching was creating a professional culture of sharing ideas, skills and attitudes among the students who are pre-service teachers. They indicated that teachers are also part of the learning situation and needed to engage their learners in constructing knowledge. The tutors believed the collaborative skills were essential in developing professional behaviours and attitudes as future teachers. The response from an interviewee was that:

If all tutors begin to use this system [online teaching mode] it will help the students a lot. In that, we will stop this idea of feeding them with information and allow them to access the information themselves. It will also build their capacity to go and teach because we are 
teaching teachers to also go and teach in the field/classroom using the latest learning styles or approaches ... [Moses, Maths].

This finding brings to light the need to encourage students to be self-directed in their learning and for tutors to be facilitators fostering self-discovery approach to learning. In other words, the finding highlights how tutors should provide initiatives to help students learn on their own by overcoming the bottlenecks to search for information and new knowledge to employ in their practice. As teacher educators, this calls for knowledge building in new ways of engaging students to learn. It also calls for faculty sensitization and capacity building in discovery learning strategies.

\subsection{Challenges in Tutoring Online}

Although tutors acknowledged the benefits and importance of adopting this mode of teaching and learning in our current context, they did not hesitate to voice out the challenges in the system. Most of them commented on the lack of efficient infrastructure, limited technical competence, insufficient capacity building and work overload. All of them were of the view that it is important to constantly develop both tutors and students in online skills of teaching and learning. This is what some had to say:

I wish the authorities will organize refresher courses to those already in the system and then try to get those who are not using the system to participate... [Reter, Maths.]

They have to look at the internet connectivity ... because the server is not helping. So if they can do something about it, it will help because a lot of people I know, some of them are not using the moodle again because they are complaining that the network is not helping so if personally you don't have that interest in it you will leave it one time... [Mijiw, S. Studies]

I think training, and then I think that support. Admittedly, there are some lecturers who are a little skeptical (techno phobia); and finally I think that lectures are busy and it takes a lot of work to set up a course, so if the lecturer is even intending to teach online, there is no incentive or motivation to get him to go through all that hustle to put the work up ... [EphAid, ICT]

Almost all the interviewees responded that there is the need to continually upgrade them in online teaching and learning since there are new tools being incorporated unto the LMSs. This confirms Zawacki-Richter's (2004) view that the development and promotion of online teaching and learning can only be realized by a support strategy that takes effect from both the top-down and from the bottom-up with the introduction of incentive systems for participation in online teaching. It was clear in their responses that tutors could be doing better as leaders and managers in the virtual environment if their skills were being sharpened through refresher courses. They could even develop certain basic skills in their students as 
they engage them in collaborative learning courses. These findings suggest that if tutors are considered as initiators in online learning environments, then their capacities should be taken seriously.

Further, the need to motivate and support tutors in playing the roles as e-tutors was emphasized by interviewees. In this instance, support and motivation in the sense of recognition and appraisal would be seen as welcoming. As commented by EphAid, (ICT), the workload of lecturers often deter some of them to develop and upload their courses online; how much more to facilitate online. These insights call for a closer look at the policy of teaching online and the benefits to be derived from doing so.

\section{Conclusion and Recommendations}

The study, which focused on exploring the experiences of the online tutor regarding their role in maintaining an effective learning environment has highlighted both positive variables and challenges that are likely to be encountered in this mode of teaching and learning. The experiences shared by some members of the pioneer cohort of online tutors at the University of Education, Winneba seem to call for a paradigm shift in lecturers' approach to teaching. The findings have brought to the fore many important issues to be addressed by managers of the initiative. The findings have provided insights into how tutors engage students on line, how they initiate learning processes and moderate students' participation in online learning. Further, it has thrown light on what is expected of tutors as facilitators, managers and leaders in the learning environment to regularly and effectively involve students in discovery mode of learning and not 'spoon-feeding' methods of teaching. As teacher educators in an era of collaborative learning, the findings have illuminated the need to shift from the solely face-to-face teaching method to the blended mode, which provides opportunities for students and tutors to be lifelong learners. Moreover, it has emphasized the need to build a learning community by providing continuous support through capacity building for both tutors and students. Although, most interviewees expressed their satisfaction in the benefits gained, they also stressed the lack of motivation and non-acknowledgement of the workload involved not neglecting the limited technical support needed. It is therefore important for implementers to provide the necessary interventions as suggested by the tutors to improve their engagement in this new mode of teaching thereby win more tutors to the initiative. It will be interesting to investigate how students also understand this new mode of teaching and its impact on their learning as well as gain further understanding into tutors' online development processes.

\section{References}

Bates, A. W. (2000). Managing technological change - Strategies for college and university leaders. San Francisco: Jossey Bass.

Bennett, S., \& Marsh, D. (2002) Are We Expecting Online Tutors to Run Before They Can Walk? Innovations in Education and Teaching International, 39(1), 14-20.

Carswell, A. D. (2001). Facilitating student learning in an asynchronous learning network. Dissertation Abstracts International, 62(03), 1110. 
Cheung, W. S., \& Hew, K. F. (2008). Examining facilitators' habits of mind and learners' participation. In Hello! Where are you in the landscape of educational technology? Proceedings ascilite Melbourne 2008. Retrieved May 2, 2014 from http://www.ascilite.org.au/conferences/melbourne08/procs/cheung.pdf

Cheung, W. S., \& Hew, K. F. (2010). Examining facilitators' habits of mind in an asynchronous online discussion environment: A two cases study. Australian Journal of Educational Technology, 26(1), 123-132. Retrieved May 2, 2014 from http://www.ascilite.org.au/ajet/ajet26/cheung.html

Denis, B., Watland, P., Pirotte, S., \& Verday, N. (2004). Roles and Competencies of the E-Tutor. Networked Learning Conference, Symposium 6, Retrieved May 2, 2014 from http://www.networkedlearningconference.org.uk/past/nlc2004/proceedings/symposia/sympos ium6/denis_et_al.htm

Doolittle, P. (1999). Constructivist pedagogy. Retrieved January 10, 2014 from http://edpsychserver.ed.vt.edu/workshops/tohe1999/pedagogy.html

Gold, S. (2001). A constructivist approach to online training for online teachers, Journal of Asynchronous Learning Networks, 5(1). Retrieved January 10, 2014 from http://www.aln.org/ publications/jaln/v5n1/pdf/v5n1_gold.pdf

Goold, A., Coldwell, J., \& Craig, A. (2010). An examination of the role of the e-tutor. Australasian Journal of Educational Technology, 26(5), 704-716.

Harman, K., \& Koohang, A. (2005). Discussion board: A learning object. Interdisciplinary Journal of Knowledge \& Learning Objects, 1, 67-77. Retrieved January 10, 2014 from http://ijello.org/Volume1/v1p067- 077Harman.pdf

Hung, D. (2001). Design principles for web-based learning; implications for Vygotskian thought. Educational Technology, 41(3), 33-41.

Hung, D., \& Nichani, M. (2001). Constructivism and e-learning: balancing between the individual and social levels of cognition. Educational Technology, 41(2), 40-44.

Koohang, A., \& Harman, K. (2005). Open source: A metaphor for e-learning. Informing Science: The International Journal of an Emerging Transdiscipline, 8, 75-86. Retrieved May 2, 2014 from http://inform.nu/Articles/Vol8/v8p075-086Kooh.pdf

Koyanagi, M. (n.d.) Putting courses online: Theory and practice. Retrieved January 10, 2014 from http://www.ils.unc.edu/disted/cmi/final2.html

Marshall, C., \& Rossman, G. B. (2006). Designing Qualitative Research (5th ed.). Thousands Oaks: Sage.

Mayer, M. (1996). Is it Constructivism? Retrieved January 10, 2014 from http://www.sedl.org/pubs/sedletter/v09n03/construct.html

McPherson, M., \& Nunes, M. B. (2004). The Role of Tutors as an intergral Part of Online Learning Support. Third, EDEN Research Workshop, Oldenburg, Germany, 2004. 


\section{Macrothink}

Journal of Education and Training

ISSN 2330-9709 2015, Vol. 2, No. 1

Moule, P. (2007). Challenging the five-stage model for e-learning: a new approach. ALT-J, Research in Learning Technology, 15(1), 37-50.

O'Hare, S. (2011). The Role of the Tutor in Online Learning in ASCILITE 2011 Changing Demands. Changing Directions, Wrest Point, Hobart Tasmania Australia 4-7 December 2011, Conference proceedings.

Pushpanathan, T. (2012). The Role of a Teacher in Facilitating E-learning. Journal of Technology for ELT, 2(2).

Woolfolk, A. E. (1993). Educational psychology. Boston: Allyn and Bacon.

Zawacki-Richter, O. (2004). The Growing Importance of Support for Learners and Faculty in Online Distance Education, In: Learner Support in Open, Distance and Online Learning Environments. Oldenburg: BIS-Verlag der, 51-62.

\section{Copyright Disclaimer}

Copyright reserved by the author(s).

This article is an open-access article distributed under the terms and conditions of the Creative Commons Attribution license (http://creativecommons.org/licenses/by/3.0/). 